\title{
Processo criativo digital: do croqui à impressão 3D
}

\author{
Digital creativeprocess: fromsketching to 3D printing
}

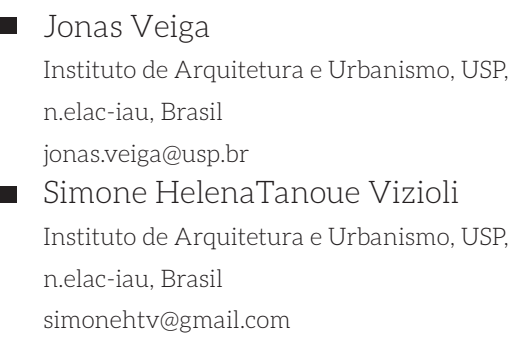

\begin{abstract}
Thisarticleaimstodiscusstheuseofdigitalmediain theprojectiveprocessfromthepreliminarysketchesondigital platformstoparametric systems andrapidprototyping. To thatend, a product design willbepresented, a bottle, in order to explainthecomplexitiesinherent in thisprocess. The practicalexperimentationwasdividedinto four stages: creativeprocess, secondproposition, parameterizationand 3D printing.
\end{abstract}

Keywords: Digital Sketching, Creativeprocess, Parameterization, Rapidprototyping, Hybrid Design

\section{Introdução}

Este artigo discute a utilização dos meios digitais no processo projetivo desde os esboços preliminares em plataformas digitais aos sistemas paramétricos e à prototipagem rápida.

O desenhar como expressão de uma ideia - o gesto como uma linguagem comprometida com o dinamismo intrínseco ao processo criativo - segue sendo um campo de experimentação enriquecedor e fundamental. Inúmeros são os pesquisadores que investigam o tema, entre eles, tem-se Gouveia (1998), Tversky (2002), e Zafer (2006), para quem os esboços têm na ambiguidade um de seus fatoreschaves, isto porque estas representações permitem novas possibilidades e também novas reinterpretações do projeto.

Na mesma linha de pensamento, para Tavares (2009), o desenho também dá ao projeto a oportunidade de transgressão, ambiguidade e crescimento. Os conceitos e as soluções projetuais dificilmente serão encontrados elou sugeridos a partir da rigidez de desenhos técnicos, mas da flexibilidade com que as linhas dos esboços rudimentares se sobrepõem, trazendo sempre novas percepções. Porém, não se pode ignorar o campo tecnológico: segundo Righi (2009), "o computador tornou-se quase que obrigatório no processo de representação de projetos, tornando as simulações virtuais e as novas mídias cada vez mais exigidas". Entretanto, após a Revolução digital, como o desenho estaria inserido neste contexto, como ele estaria inserido nas discussões de projeto?
Será esta a discussão proposta por este texto. Atualmente, novas ferramentas têm sido inseridas no mercado com o intuito de aliar o desenho manual com o desenho digital permitindo o constante fluxo das ideias, próprio desta linguagem que se utiliza de linhas como verbo. Ferramentais tais como a Inkling, diversos tipos de tablets, ou ainda a Cintiq, na qual a precisão do traço aplicado sobre a tela é análoga ao traço feito no papel, mantém o croqui como uma assinatura individual, inalienável.

Para além destas ferramentas que podem auxiliar o processo de projeto, este artigo aborda o processo paramétrico. Processo que, sob determinada perspectiva, rompe com a autonomia dada pelas mãos de quem desenha, de quem domina a forma por suas próprias intenções, uma vez que delega a uma máquina, por meio de códigos, a concepção criativa de um determinado produto.

Por fim, discute-se a prototipagem rápida. Uma vez elaborados modelos digitais de um dado produto, é possível materializá-lo por meio da impressão 3D. O que préanuncia um grande avanço no campo do processo criativo, permitindo o aprimoramento constante até que sejam atingidas as características desejadas do objeto em estudo.

O desenho em meio digital

A tela que antes era mediada apenas pelo mouse agora permite sua interação com a ponta dos dedos, ou como em um papel, com uma caneta apropriada. Deste modo, as novas ferramentas digitais também permitem várias opções de representação, acrescidas de novas possibilidades, 
mesmo que a mudança seja apenas de suporte (mesa digitalizadora). São recorrentes as comparações entre o uso de desenho de processo feito à mão e aquele desenvolvido no computador. Podem ser citados os trabalhos de Elliott e Hearst (2002), Righi (2009), e Celani (2007) que analisam como a tecnologia interfere no processo projetivo.

Juntamente com o desenho, a modelagem paramétrica, onde parâmetros como distâncias, ângulos e outras equações são usados para compor um modelo, tem se mostrado uma importante ferramenta no processo criativo. Como afirma Moreira (2011), a ação de decidir é fundamental no projeto, assim, "esses testes permitem, dentro do espaço de soluções, verificar qual dos modelos resolve melhor o problema de projeto" (ANDRADE, RUSCHEL. 2011. pp.425-426).

Desenho e parametrização são duas ferramentas distintas, porém, complementares, que tencionam para uma mesma finalidade, a completa saturação dos problemas encontrados no desenvolvimento de um projeto. Aliado a estas ferramentas tem-se o modelo tridimensional físico, pois contribui para a visualização de um objeto real, sanando todas as possibilidades de erro, bem como representando um "papel importante como estratégia no desenvolvimento e na materialização das ideias do arquiteto". (OLIVEIRA, FABRÍCIO, 2011, p. 457)

Como Righi (2009) ainda defende, "a exploração formal possibilitada por ferramentas como digitalizadores 3D, máquinas de prototipagem rápida, impressoras a laser, estimulam os alunos a buscar inovações." Portanto, o processo criativo pode passar por várias ferramentas, desde o desenho livre que pode expressar uma desnaturalização do olhar e abrir-se para novas possibilidades, passando pelos sistemas generativos que trazem em sua essência a escolha e a exclusão; até a prototipagem rápida, e a impressão 3D; meios diferentes que convergem para um mesmo fim, o desenvolvimento pleno de um projeto.

\section{Metodologia}

Para uma melhor compreensão do processo híbrido aqui discutido, é apresentado o projeto de uma garrafa como estudo da aplicação de diferentes ferramentas e modos de operação. A mesa digitalizadora Cintiq foi escolhida como plataforma inicial para a experimentação projetual por promover melhores condições ao desenho à mão livre devido à sua maior interatividade entre o produto inicial, croqui, e o produto final, sólido digital 3D. $\mathrm{O}$ caminho entre tais produtos teve quatro etapas em sua sequência, as quais se evidenciam pelo processo criativo, reproposição, parametrização e impressão 3D (ver figura 1).
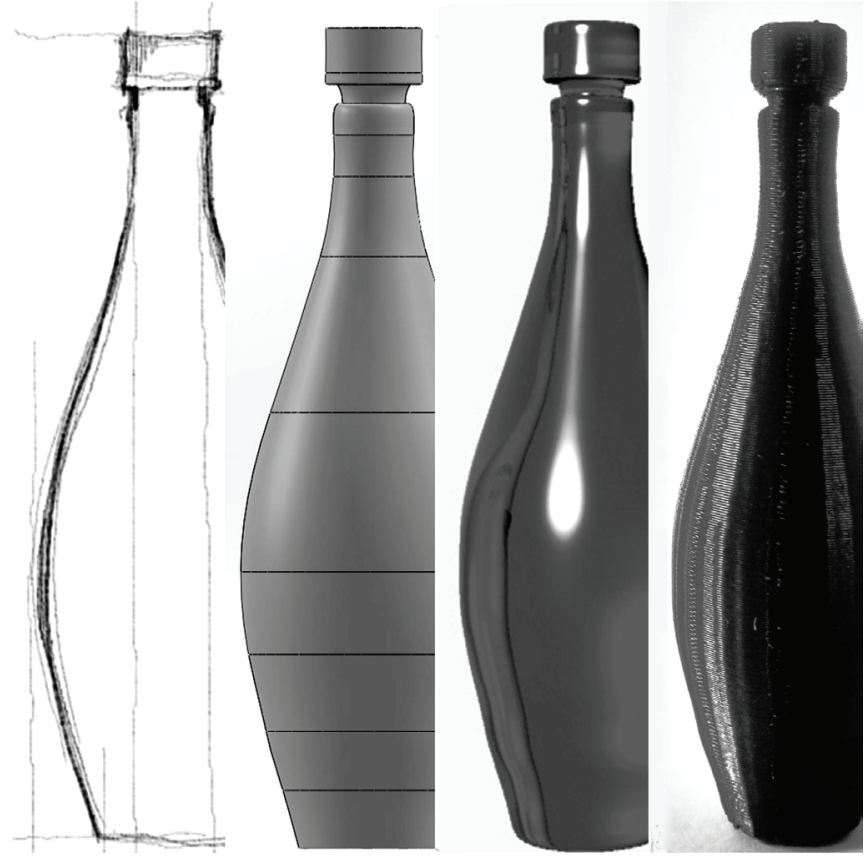

Figura 1: Croqui; modelo digital SolidWorks; modelo digital parametrizado Grasshopper; modelo físico impresso. Fonte: VEIGA, J. n.elac, IAU.USP. 2014.

\section{Processo criativo}

A primeira etapa da experimentação - processo criativo - teve como base três diferentes programas de edição de imagem: Sketchbook Pro, Adobe Illustrator, e Solidworks para execução dos desenhos livres onde se fizeram presentes tanto o repertório do projetista, como sua percepção, cognição e expressão sobre o objeto a ser projetado.

A linguagem universal comumente utilizada no discurso dos arquitetos, em meio às pranchetas, lápis e papeis, também foi utilizada como ponto de partida para este desenvolvimento projetivo. Entretanto, longe da trama que compõe o papel, os esboços foram realizados na Cintiq, através do software Sketchbook Pro. Uma vez que os traços que delinearam os limites da forma foram esboçados, estes passaram por um processo de decodificação digital por meio do AI (Adobe Illustrator), sendo, em outras palavras, vetorizados. Apesar de vetor, a forma ainda não se configurava em volumetria. Um eixo latitudinal dividiu pelo centro as linhas que pertenciam ao contorno da garrafa, e, com a revolução dos traços vetorizados foi possível criar, usando um terceiro software, Solidworks, a superfície tridimensional do objeto em estudo.

\section{Reproposição}

A segunda parte do processo projetual, reproposição, teve 
como foco o a cíclica rediscussão do objeto de estudo, uma vez que a ret roalimentação do processo é etapa fundamental na concepção de um produto. Assim, tomando como base o exercício de processo criativo, foram desenvolvidos os mesmos fundamentos. O produto final criado no exercício anterior foi criticadoe, a partir dele, foi reproposto um novo produto (ver figura 2) através dos programas SketchbookPro, Illustrator e Solidworks.
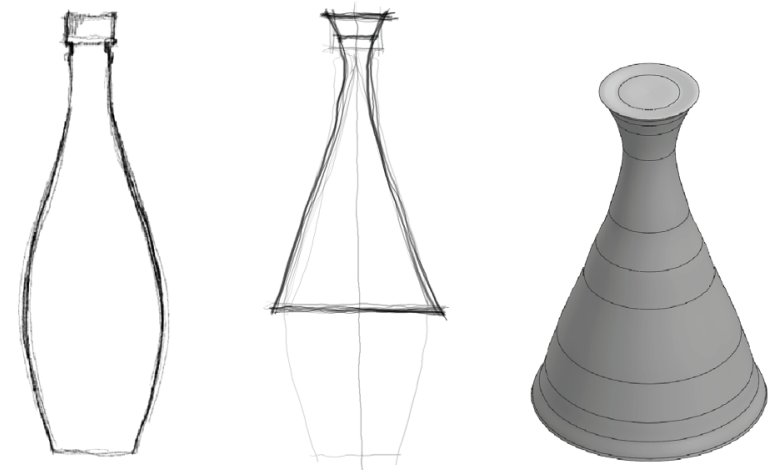

Figura 2: Croqui; estudo de reproposição; novo modelo digital Solidworks. Fonte: VEIGA, J. n.elac, IAU.USP. 2014.

Entretanto, o fato de ter criticado a primeira forma projetada, elaborando outra a partir dela, não significa que o resultado subsequente tenha sido melhor, ou tenha atendido de maneira mais adequada às necessidades do projeto, seja formal ou funcionalmente. A crítica e, logo, a reproposição, se instituem ora como melhoria, ora como reafirmação da forma original. Deste modo, embora tenha sido criado um novo modelo, como observado na figura acima, optou-se pela manutenção da primeira garrafa devido à sua questão estética.

\section{Parametrização}

A parametrização, método utilizado ao longo da terceira etapa, trouxe uma contribuição inovadora para o processo projetivo. Este método, de um modo geral, pressupõe a total codificação dos vetores construídos em parâmetros, para isso, os traços vetorizados anteriormente no Illustrator precisaram ser exportados para outro software, Rhinoceros. $\mathrm{Na}$ realidade, este último software apenas traduz para a tela os procedimentos de parametrização realizados em seu pluggin, Grasshopper, onde fora feito, de fato, a decodificação dos vetores em múltiplos pontos e sua consequente transformação em parâmetros.

Parte do processo se assemelha à construção da garrafa no programa Solidworks, seguindo fielmente o croqui para figurar à geometria tridimensional por meio da revolução em torno de um eixo. A diferença, salvo a etapa de revolucionar, é dada pela modificação destes pontos, criando-se um script (ver figura 3) que permitisse suas alterações.

A construção de tal script embasou-se em dois importantes fatores, ou, no caso, parâmetros, que exaltaram a transformação do design original do objeto. $O$ primeiro parâmetro foi a modificação tanto do diâmetro da base, quanto do centro da garrafa; o segundo é caracterizado pela movimentação de ambas circunferências, sem alterar a altura do objeto. Consequentemente, deixando variáveis o diâmetro e sua posição no eixo vertical, foi possível criar infinitas formas, sem passar pelo processo de concepção dado pelos croquis. Esta etapa trouxe a discussão sobre os processos e reprocessos a partir de um único código gerado, script, utilizando o plugin Grasshopper pelo software Rhinoceros.

Dentre as possibilidades que emergiam como forma para as garrafas, foram escolhidos quatro modelos distintos (ver figura 4). Logo, com o Grasshopper, não houve a necessidade de elaborar novos esboços que rediscutissem um primeiro modelo, repropondo e criticando-o para dar início à novas criações, apenas com a mudança de determinadas variáveis, uma nova garrafa poderia serproduzida, ficando a critério do criador única e exclusivamente a escolha da geometria que melhor lhe conviesse.

É inegável que o plugginGrasshopperadmite inúmeras possibilidades de trabalho, de formas, funções, e deformações, entretanto, deve-se considerar o grau de dificuldade de sua utilização. Assim, percebe-se a ocorrência da globalização da

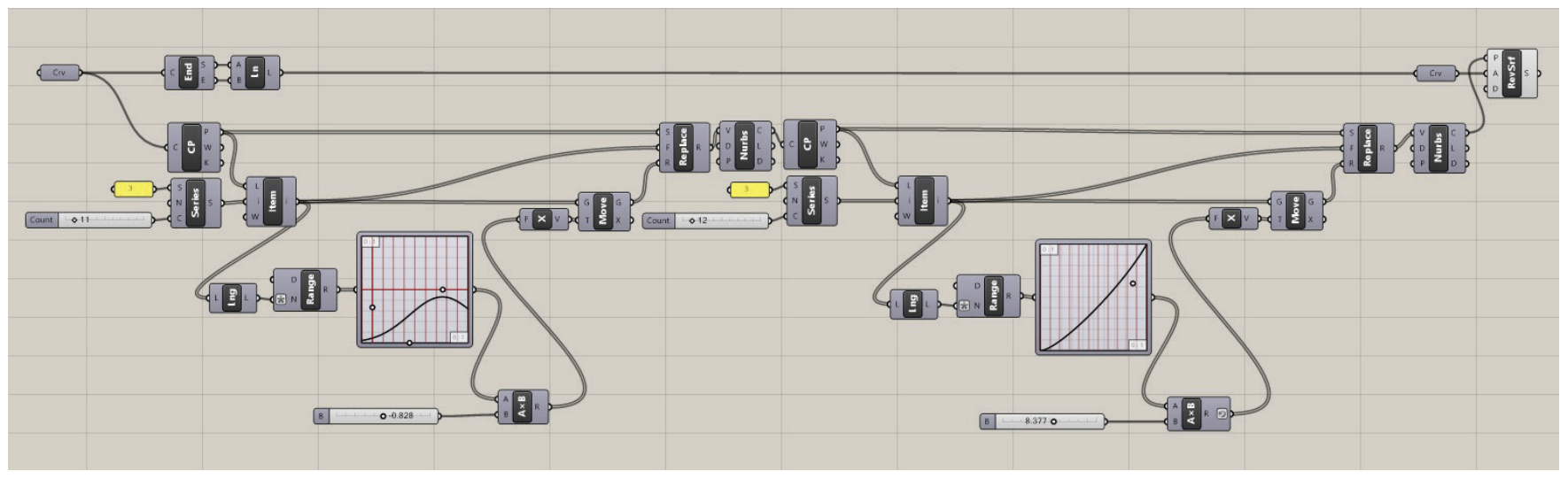

Figura 3: Script Grasshopper para a parametrização da garrafa. Fonte: KIM, H. e VEIGA, J.; n.elac, IAU.USP. 2014. 
informação e da socialização do conhecimento, promovendo o aporte mútuo entre os usuários do programa.Sites, como grasshopper3d.com, reúnem pessoas dispostas a partilharem seus conhecimentos para suprirem as possíveis dúvidas que por ventura apareçam no decorrer da programação a ser feita.

\section{Impressão 3D}

Uma vez selecionadas as garrafas pelos seus aspectos formais, a quarta fase - impressão 3D - foi realizada no laboratório do grupo de pesquisa NOMADS, do Instituto de Arquitetura e Urbanismo da Universidade de São Paulo. Assim, pôdese imprimir e realizar uma análise comparativa das quatro formas geradas, não apenas bidimensionalmente pelos desenhos ou pelas maquetes digitais, mas uma análise física e tridimensional das garrafas estudadas (ver figura 4).
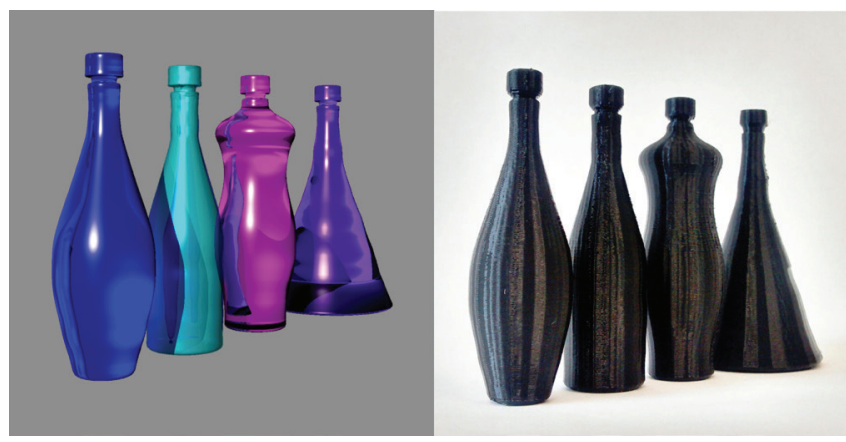

Figura 4: Comparativo entre modelos digitais renderizados em Rhino e modelos impressos tridimensionalmente. Fonte: VEIGA, J. n.elac, IAU.USP. 2014.

A prototipagem rápida pré-anuncia um grande avanço no campo do processo criativo, permitindo o aprimoramento constante até que sejam atingidas as características desejadas do objeto em estudo.

\section{Resultados}

O tato, bem como a visão, são instrumentos poderosos para o julgamento de um bom projeto. Agora, já não será mais preciso esperar que este seja finalizado para apontar erros na concepção de um produto, pois sua materialização através da impressora 3D pode antever aquilo que na tela do computador ou sob as camadas de papel ficou obscurecido, realizando, finalmente, as modificações necessárias para sua conclusão.

\section{Conclusão}

Pode-se concluir que a presença do desenho ainda é fundamental para o processo projetivo, independentemente do meio em que ele é executado, seja no papel, seja numa plataforma digital, como a Cintiq.

As primeiras duas etapas do projeto de criação e reproposição da garrafa mostraram a potencialidade que o universo digital oferece, permitindo desenvolver e produzir qualquer objeto mantendo-se as potencialidades criativas iniciais do croqui. As duas últimas etapas, parametrização e impressão 3D, evidenciaram a facilidade de remodelação e de obtenção de modelos para estudos, potencializando o processo projetivo. Contudo, parte do processo de parametrização rompe com a autonomia dada pelas mãos de quem desenha, de quem domina a forma por suas próprias intenções, de quem não delega a uma máquina a concepção criativa de um dado produto.

O caminho percorrido ao longo do processo projetual híbrido mantém a poética presente na leveza das mãos daquele que desenha, aliando-se ao potencial tecnológico das máquinas. A sabedoria humana se adapta e extrai as melhores condições de cada etapa na busca incessante da excelência.

\section{Agradecimentos}

À Pró-reitoria de Graduação pelo financiamento à pesquisa; ao Instituto de Arquitetura e Urbanismo da USPAU. USP; ao Núcleo de Apoio a Pesquisa para os Estudos em Linguagem da Arquitetura e Cidade, N.ELAC; ao Núcleo de Estudos de Habitares Interativos, NOMADS. - IAU.USP

\section{Referências}

ANDRADE, Max L. V. X.; RUSCHEL, Regina Coeli. Capítulo 21: BuildingInformationModeling (BIM). Livro: O processo de projeto em arquitetura: da teoria à tecnologia. Organizado por KOWALTOWSKI, Doris C.C.K. Ed. Oficina de Textos, dez. 2011 Celani, G.; Godoi, G.; Rodrigues, G. (2007). O processo de projeto arquitetônico mediado por computador: um estudo de caso com o Architectural Desktop. GRAPHICA. Curitiba.

ELLIOTT, A.; HEARST, M. A. 2002. A ComparisonoftheAffordancesof a Digital Desk and Tablet for ArchitecturalImageTasks. InternationalJournalofHumanComputer Studies. Volume 56 (2) (pp 173-197). Academic Press, Minessota, EUA

GOUVEIA, Anna Paula silva. O croqui do arquiteto e o ensino do desenho.1998. Tese (Doutorado) - Faculdade de Arquitetura e Urbanismo, Universidade de São Paulo, Volume I - Croqui: representação e simulação, São Paulo, 1998.

KIM, H.; VEIGA, J. Figura 3. Script Grasshopper para a parametrização da garrafa. Fonte: KIM, H. e VEIGA, J.; n.elac, IAU.USP. 2014.

MOREIRA, Daniel de Carvalho. Introdução. Livro: O processo de projeto em arquitetura: da teoria à tecnologia. Organizado por KOWALTOWSKI, Doris C.C.K. Ed. Oficina de Textos, dez. 2011

OLIVEIRA, Marina Rodrigues; FABRÍCIO, Márcio M. Capítulo 23: Projeto paramétrico e prototipagem rápida: casos em instituições internacionais. Livro: $\mathrm{O}$ processo de projeto em arquitetura: da teoria à tecnologia. Organizado por KOWALTOWSKI, Doris C.C.K. Ed. Oficina de Textos, dez. 2011 RIGHI, T. A. F. Displays Interativos como ferramentas de comunicação no processo de projeto de arquitetura. Dissertação de Mestrado - Universidade Estadual de 
Campinas, Faculdade de Engenharia Civil, Arquitetura e Urbanismo. Campinas, 2009

RIGHI, T. A .F; Celani, G. Esboços na era digital: uma discussão sobre as mudanças na metodologia de projeto arquitetônico. Congresso Iberoamericano de gráfica digital SIGRADI. In Anais... Havana Cuba 2008.

TAVARES, Paula - O desenho como ferramenta universal. $O$ contributo do processo do desenho na metodologia projectual. Revista de estudos politécnicos, 2009, Vol VII, n¹2, 007-024.
VEIGA, J. Figura 1. Croqui; modelo digital SolidWorks; modelo digital parametrizado Grasshopper; modelo físico impresso. Fonte: VEIGA, J. n.elac, IAU.USP. 2014.

VEIGA, J. Figura 2. Croqui; estudo de reproposição; novo modelo digital Solidworks. Fonte: VEIGA, J. n.elac, IAU.USP. 2014.

VEIGA, J. Figura 4. Comparativo entre modelos digitais renderizados em Rhino e modelos impressos tridimensionalmente. Fonte: VEIGA, J. n.elac, IAU.USP. 2014. 